\title{
Trilingual education in China: perspectives from a university programme for minority students
}

Article

Accepted Version

Liu, J. and Edwards, V. (2017) Trilingual education in China: perspectives from a university programme for minority students. International Journal of Multilingualism, 14 (1). pp. 38-52. ISSN 1747-7530 doi:

https://doi.org/10.1080/14790718.2017.1258983 Available at https://centaur.reading.ac.uk/69270/

It is advisable to refer to the publisher's version if you intend to cite from the work. See Guidance on citing.

Published version at: http://dx.doi.org/10.1080/14790718.2017.1258983

To link to this article DOI: http://dx.doi.org/10.1080/14790718.2017.1258983

Publisher: Taylor \& Francis

All outputs in CentAUR are protected by Intellectual Property Rights law, including copyright law. Copyright and IPR is retained by the creators or other copyright holders. Terms and conditions for use of this material are defined in the End User Agreement.

www.reading.ac.uk/centaur 
Central Archive at the University of Reading

Reading's research outputs online 


\section{Trilingual education in China:}

\section{perspectives from a university programme for minority}

\section{students}

\section{Abstract}

Attention to trilingual education programmes in China has tended to focus on basic education; there had been little attention to date on the higher education sector. This paper will attempt to bridge this gap by exploring a Yi-English-Chinese trilingual education programme through case studies of three Yi students, using the 'River of Life' constructivist technique - where participants map turns on a river to represent critical incidents in their life histories - to promote reflection. The findings focus on life events, such as family relocation and change of schools, which steered students to the trilingual Yi-English-Chinese programme; the different ways in which students position themselves in relation to the three languages; and the implications of mixed ability classes, limited teaching resources and the absence of appropriate pedagogies. While the delivery of the programme presents serious challenges and the learning outcomes are often disappointing, the pragmatic gains associated with the programme are substantial in terms of students' access to employment in their home region and opportunities for further study.

\section{Key words}

Trilingualism, ethnic minorities, higher education, China, Yi 


\section{Trilingual education in China:}

\section{perspectives from a university programme for minority}

\section{students}

\section{Introduction}

Attention to trilingual education programmes in China has tended to focus on basic education; there had been little attention to date on the higher education sector. The present paper will attempt to bridge this gap by exploring a Yi-English-Chinese (YEC) trilingual education programme through case studies of three Yi students. We will start by briefly exploring multilingualism and minority participation in higher education in China, contextual issues important for an understanding of trilingual education. We will then describe the methodology employed to collect data from the students before analyzing the life events which steer them to the programme, the ways in which they position themselves in relation to the three languages, and the implications for the delivery of the programme and the learning outcomes of students.

\section{Trilingual education in China}

Two background issues need to be explored in order to provide a context for the current study: the first concerns the extent of linguistic diversity in China; the second relates to the nature of minority ethnic participation in higher education.

\section{Multilingual China}

Some 56 different ethnic groups are officially recognised in China, of which the Han form by far the majority. The 55 minzu (ethnic minorities) make up over 8 per cent of the total population, over a hundred million people. Found predominantly in the western borderlands of the country, these minority communities differ considerably in terms of history, culture and language (Dai et al., 2000). The Yi, who form the focus 
for the present study, constitute the sixth largest group, numbering over eight million.

It is commonly assumed in the west that China is a linguistically homogeneous nation where the entire population speaks 'Chinese'. While it is true that everyone is exposed through the education system to what is variously referred to as Mandarin, Putonghua (common speech) or Standard Modern Chinese, such an assumption is a gross oversimplification. Mandarin is indeed the most common variety, spoken by an estimated billion people (Lewis et al., 2015). However, it coexists with a number of other mutually unintelligible regional varieties including Wu, Cantonese, Hunan, Hakka, Gan, Southern Min and Northern Min. This confusion has led writers, such as Lewis et al. (2015) to classify Chinese as a whole as a 'macrolanguage'. Mair (1991) takes an alternative approach, adopting topolect (i.e. 'the speech form of a particular place' and a literal translation of the Chinese term fāngyán 方言), to defuse the confusion that arises as a result of its mistranslation as "dialect". A topolect, then, is a set of similar dialects (e.g. those of Beijing and Nanjing), which is distinct from $\mathrm{Wu}$ or Cantonese or any of the larger distinct regional varieties of a language.

In addition to these topolects, over 80 languages, associated with the 55 minzu have been recognized. The situation is complicated still further by the emergence of codemixing varieties such as Tuanjie Hua in Sichuan, which draws on Yi and the topolect and is used mainly in informal contexts (Tsung, 2012).

Two types of bilingual education have emerged in China in response to this linguistic diversity: the first is targeted at minority populations and involves the teaching of Mandarin Chinese and an ethnic minority language; the second, targeted mainly at the majority Han population, involves Mandarin Chinese and English in recognition of its growing importance as a global language (Feng, 2005, 2007). In both contexts, however, the situation is further complicated by the fact that teachers in rural areas are more likely to use the topolect than Mandarin while teachers in urban areas are likely to code switch between Mandarin and non-Mandarin topolects. In the present study for instance, Yi students will be exposed to both Mandarin and Sichuanese. For reasons of simplicity, however, we will use 'Chinese' throughout to refer to this codeswitching behaviour. 
The current interest in English has been a catalyst for scholarly interest in Sanyu Jiantong (trilingualism or mastery of three languages: the indigenous minority home language, Mandarin Chinese, and English) (Feng, 2012, p. 6). The most notable contribution to date has been the 'Models of Trilingual Education in Ethnic Minority Regions of China' project undertaken by a national network of researchers in ten key regions (see, for instance, Adamson \& Feng, 2009; Cenoz, 2014). The main focus, for this project, however, has been basic education. The present paper, in contrast, focuses on trilingualism in tertiary education. As such, it can be seen as central to the theme of this special issue on adult multilingualism.

\section{Minority participation in higher education}

A brief discussion of minority participation in higher education is essential for an understanding of trilingual programmes in universities. At the societal level, as Yu, Stith, Liu, and Chen (2012, p. 7) observe, education has traditionally played an important role and learning "has always been highly valued and respected"; at the level of the individual, the pursuit of knowledge is considered fundamental to social and economic mobility (Liu, 1998). In some developed regions and areas such as Shanghai, over half of the families hope that their children will be able to enroll in diploma or degree programmes (Hu, Fu, \& Zhang, 2003).

The rates of enrolment of minorities, however, compare unfavourably with those of the Han majority. Various factors can explain this trend, not least the economic situation in minority dominated regions struggling to maintain "a meager subsistence" (Teng, Yang, \& Yang, 2014, p. 188). In an attempt to create a more level playing field, many universities award extra points to minority students in entrance examinations and set recruitment targets (Wang, 2015).

The YEC programme at the case study university distinguishes between Model I applicants who have received a significant part of their basic education in Yi, and Model II students whose basic education is in Chinese. As part of a policy of positive discrimination, Model I applicants are allocated more points than Model II applicants in university and college entrance examinations; their chance of being admitted is therefore much greater. Nevertheless, the number of Model I applicants recruited for the 
YEC programme is very limited, usually four to five students each academic year. This is not surprising given that the number of the students who receive Model I basic education is very small, especially when compared with the number of Model II students (Li, Hai-Lai, Liao, \& Luo-Hong, 2015; Zhao, 2015). It is also the case that those who achieve the top scores tend to apply to higher status Han dominated universities. Model II students enjoy fewer privileges than their Model I peers and they need to take the Yi entrance exam for the YEC programme. Yet, the admission threshold cut-off scores is set very low. Furthermore, other than a threshold score in the Yi entrance exam, there are no minimum requirements for admission for Model II students. Admission is based on a rank ordering of applicants. Under these circumstance, many students who are actually very poor in Yi reading, writing and even speaking (though presumably having basic listening skills and been born in a Yi family at a Yi-dominated region) are admitted to the YEC programme.

Given the limited number of vacancies for Model I applicants, the University sets cutoff scores for admission to the YEC trilingual programme. However, there are no minimum requirements for admission for Model II students, which means that even students with very low levels of competence in Yi are admitted. When interviewed as part of the larger project of which the current study forms a part (Liu, forthcoming), the Dean explained the situation in the following way:

\section{我们不能说你 (是成绩) 差的同学我们就不收, 比如说。。。今年给的指} 标是 180 个, 我必须要招够这 180 个, 即使最后到了多么低的一个分数段。 We cannot refuse [applicants] because [they] are underachievers. For example... this year [2014], the official recruitment target is 180. I therefore must recruit 180 [Yi students], regardless of how low their scores are.

For the Model I or Model II applicants with lower scores, then, the programme that forms the focus for this study is clearly the best option. As a student who took part in a focus group discussion, also part of the larger study, remarked: "这个专业就是我们分数 能够达到的最好的一个二本了, 其他的二本都要比这个学校高 [This is the best 
programme in the second-grade ${ }^{1}$ colleges and universities that we can enroll on with our marks. All the other programmes have higher entry requirements than this University]". Significantly, however, while committed to the promotion of Yi language and culture, the Dean chooses to see this situation in terms of an opportunity rather than a problem:

\section{国家政策许可，那些孩子有机会上大学我为什么要不准他们上大学呢，对 \\ 吧？200分也好，300分也好，他有机会上大学。}

Since recruitment complies with government policies and those children have an opportunity to go to university, why should I turn them down? Irrespective of whether [they] scored 200 or 300 , the chance to study in university is there for them.

The fact that students' choice of programme was pragmatic, does not, of course, diminish their interest in Yi language and culture; many reported, for instance, that they could only achieve a sense of belonging and intimacy when studying in a minority dominated university. The poor educational achievements of the students on entry, together with their varying levels of competence in Yi, however, potentially compromise both the delivery of the programme and the learning outcomes of students.

\section{Research questions}

As already mentioned, the research reported in this paper is part of a larger project which aims to explore and identify both challenges and good practice in this particular programme (Liu, forthcoming). For present purposes, however, we seek to dig deeper, looking at the situation through the lens of just three students. In particular, we attempt to use their experiences to answer the following questions:

- What life events steer students to the trilingual YEC programme?

- How do students position themselves in relation to the three languages of the programme?

\footnotetext{
${ }^{1}$ In China, colleges and universities are ranked as first grade, second grade, and third grade according to the overall capability and teaching and research strength. As a result, the entry requirements can vary significantly across the three grades.
} 
- What are the implications for the delivery of the programme and the learning outcomes of students?

\section{Methodology}

While the larger study draws on interviews and focus group discussions with a wide range of students across the programme and the teachers and administrators responsible for its delivery, in the present paper we analyze interview data collected using the River of Life technique to explore the language and learning histories which have a bearing on how students experience the programme.

The River of Life is a constructivist technique used to promote reflection on important events in the life history of participants (Denicolo \& Pope, 1990; Pope \& Denicolo, 2001). Participants are asked to draw a winding river. Each turn on the river represents an "important event, person, object or anything at all that influenced [participants'] attitudes and beliefs" (Cabaroglu \& Denicolo, 2008, p. 31). A few words are written on each turn to illuminate what triggered the change or development.

Just like interviews or focus groups, River of Life enables participants to use their own words to explore their experiences, opinions and concerns. One of its biggest advantages is that it sheds light on personally important issues (Cabaroglu \& Denicolo, 2008; Pope \& Denicolo, 1986) or 'critical incidents' (Denicolo \& Pope, 1990), helping students to reflect on their learning experiences and to tap into data which "otherwise would be difficult to access" (Cabaroglu \& Denicolo, 2008, p. 39). Most importantly, River of Life illustrates the influences of the past on where a participant is today. The main aim of employing this technique in the present study, then, is to identify, in participants' own words, what has led to their present positive or negative learning experiences in the programme (see Appendix for sample drawing).

Three participants were selected from the seven students who completed River of Life drawings as case studies in order to illustrate the wide range of linguistic and educational experiences represented in the larger group. 


\section{Findings}

The vignettes which follow explore the personal circumstances, linguistic background and educational experiences of three case study students - A Hai, Xiao Fang and Hei $\mathrm{Ga}$ - who represent the range of students included in the study.

\section{A Hai}

A Hai is a Model II student in his fourth year of study. His River of Life drawing starts at the age of six and ends with his funeral arrangements; it charts his journey from an innocent little boy to his dreams of being a professor, writer and poet.

Like many other Yi students, A Hai comes from a small, remote village in the Liangshan Autonomous Prefecture, a Yi dominated region in Sichuan province in Southwestern China; he frequently described himself as “懂事[sensible and well-behaved]”. In primary school, Chinese was taught by Yi teachers through the medium of Yi and the Sichuanese topolect; other subjects were taught by Han teachers in Chinese. Poverty and hardship in childhood made him a very hard-working child. However, his early academic achievements were unpromising and he needed to repeat the first year of primary education three times. His persistence was ultimately rewarded when he graduated from primary school with the highest score in his class.

In A Hai's secondary education, Chinese completely replaced $\mathrm{Yi}$ as the language of instruction even for the Yi teachers, while Yi was taught as a subject. His class teacher in junior middle school, a Han who didn't understand Yi, required all students to speak Chinese to her. A Hai recalled: "她说，你们这样是对我不尊重。。。我就觉得她怎 么会有这种想法, [说彝语]怎么就是对她的不尊重呢? She said if you did [speak Yi], that shows no respect to me ... Then I thought why does she feel like that? How could [speaking Yi to her] mean no respect"?

Many Yi people move between villages and towns to cities in the hope, among other things, of accessing a good education for their children. When A Hai was 16, his mother followed this pattern and paid fees so that he could attend a good senior middle school 
in Xichang, capital city of Liangshan. He felt both excited and anxious at this move. His failure to get on with his peers and his feeling of shame and embarrassment as a feepaying student made it difficult to study. Teachers often scolded him in front of other students, which badly affected his confidence. Although he still worked hard, he did not perform as well in the new school as in the past. A Hai summarised his three years in senior middle school as: "不堪回首的高中生涯[High school life which is unbearable to look back at]".

A turning point came when A Hai helped in his aunt's shop and came across the book The Scroll Marked which greatly inspired and encouraged him. As he repeated the third year of senior middle school, he read a wide range of literature, including the books of Lu Yao and, in particular, Life, and The Ordinary World. This exposure to Chinese literature was no doubt responsible for A Hai's strong communication skills in Mandarin. After a poor start to his educational journey, things started to improve when he was admitted to the YEC programme: his River of Life drawing suggests that the most enjoyable period of time to date was during his four years at university. A Hai observed: “我的大学生活（19-23 岁），可能是[我]一生中最愉快的时光：母语，民族， 文化身份的确立[My university life (19-23 years old) may be the happiest time of my life: my mother tongue, and the establishment of [my ethnic] cultural status]". This comment neatly summarizes the significance of the YEC programme for A Hai. The rewards are numerous: an understanding of the values of Yi culture and language; the ability to speak English to foreigners; his identification with indigenous religious practices; and admission to a good graduate school in China. A Hai talked in terms of his growing confidence:

不怕你笑话, 我自从进入这个大学后就不是自信了, 而是太过自信。因 为通过吉布老师他们，我了解了我族人的历史。虽然不是很透彻，但我 碰到这些东西了，以前是绝对不会碰这些的。而且有一种做学生、像学 术一样的思维影响到我脑壳去了。因此, 我就开始对自己的文化很自信。 所以当有人谈到彝文、彝族文化不行的时候, 我会据理力争, 去反驳。 
Maybe you will be amused [by my boldness]. Since I started University, I've become not confident but over-confident. Through teachers such as Teacher Jibu [the Dean], I know the history of my people. Although my understanding is still limited, I've had access to knowledge which it was never possible to access before. In addition, being a student or being academic is deeply affecting my way of thinking. So I have gained confidence in my own culture. At any time, when people look down upon Yi culture and Yi language, I try my best to defend it.

A Hai's proficiency in Yi was not perfect. He considered that his Yi writing skills, for instance, were at an elementary level, something which he attributed to an overemphasis on Chinese in education. In a personal email, he wrote:

我们彝人的彝语言思维模式从七岁就开始受到汉人汉语言思维模式的挑 战。而接下来, 初中、高中、大学以至到硕士, 博士, 汉语已经越来越 占据你的头脑, 而你头脑中原本拥有的那点脆弱的彝语言思维逻辑模式 早就被“侵略”，完全被强势的汉语给“征服”了。

The Yi way of thinking, in Yi, has been challenged by the Han way of thinking, in Chinese, since we were around seven years old. After that, your experiences in junior middle school, senior middle school - and even in postgraduate or doctorate programmes - the way you think is influenced more and more by Han language which "erodes" your poor fragile residual thinking in Yi. And this way of thinking in Yi eventually gives way to the dominant Han language.

Just as the Dean had argued, participation in the YEC programme had the potential to open doors and, as A Hai commented: "我觉得我们学院有些教授给我影响太大了, 我希望像他们那样[I feel that some of the professors in our college have had such a great impact on me that I hope I can be one of them one day]". His next goal is to apply for a PhD programme in Peking University in the field of Modern Chinese Literature. At the end point in his River of Life, he wrote a poem:

\section{永远是这样，风后面是风，天空上面是天空，道路前面还是道路！}

Forever is forever; Wind will follow wind; Sky is above the sky; and ahead of the road is the road! 


\section{Xiao Fang}

Xiao Fang is a Model II student in the first year of the YEC programme, the daughter of a Yi father and a Han mother. Although she spent the first years of her life in Zhaojue county, in the Liangshan Yi Autonomous Prefecture, she moved shortly after starting school to Meishan, a Han majority city in Sichuan province, to live with her Han maternal grandparents. Thus, all of Xiao Fang's peers in primary and middle schools in Meishan were Han and Chinese was the medium of instruction. She commented: "本来 年级就比较小，又跟着[汉族的]外公、外婆，就感觉自己比较[像]汉族，也没意 识到自己是彝族[Anyway I was very young, growing up with my [Han] grandparents. I therefore felt I was closer to the Han. There was no awareness of my Yi identity, either]". When asked how she felt about her Yi hometown when she went back for holidays, her answer focused on its inaccessibility: "坐车很难受, 路也不好走。妈妈过来很恼火, 我回去也很恼[The coach was very uncomfortable. The road conditions were bad as well. It was a nightmare [journey] ]". Yi, then, played a very modest role in Xiao Fang's identity in childhood and early adolescence. When asked how she perceived her ethnicity, she answered: "我觉得我更像汉族[I feel I am more like the Han people]".

Xiao Fang's father never spoke to her in Yi; her main exposure to the language, then, was through visits to the family. On the death of her maternal grandparents when she was 17 , she moved back to Zhaojue to join the third year of middle school where she experienced bilingualism within an educational context for the first time. Her limited knowledge of the language often left Xiao Fang feeling, in her words, “很尴尬[very embarrassed]", in front of Yi peers. Although the medium of instruction in her new school was Chinese, she was also able to attend taster sessions on Yi culture. She also paid more frequent visits to her paternal grandmother's house where she was exposed to Yi language and culture, including religious rituals. These experiences awakened a greater identification with the Yi people.

As the child of a mixed marriage, Xiao Fang was well placed to comment on the different values of the Han and Yi and the associated differences in status. She attributed the tensions in her parents' marriage to these differences: 
我从爸爸妈妈的婚姻看到：嫁一个人就跟嫁一个家庭一样，很多生活方 式和习惯不一样。

On the basis of my mum and dad's marriage, I feel that marrying someone is like marrying their whole family. But there are too many differences in ways of life or habits.

Differences in opinion between her parents emerged, too, on a number of other issues. Xiao Fang's father, like the majority of her YEC peers' parents, hoped that she would go back to Liangshan to work as a civil servant. Yet, her mother, like many Han parents, hoped that she could leave home and explore the world:

我妈就不喜欢[像我爸]那样。她觉得我应该去更远的地方，甚至不仅限于 四川。她觉得有能力就该去外面四处看看。就算最后回来，再苦再累， 都要出去看一下。

My mum does not think [like my dad]. She thinks I should go to somewhere far away [from home] and even beyond Sichuan. She thinks as long as [I] have the ability, I should go out and see the world. Even if in the end, [I] have to come back, it's worth doing, regardless the pain and effort.

Despite her main self-identification as Han, she was clearly proud of the history and achievements of the Yi, their culture and their language. She also sympathised with the wide range of problems they encountered:

汉族看不起彝族，彝族也看不起汉族。在外边彝族名声也不好，经常偷 东西、贩毒。我们昭觉是个艾滋病县。

The Han look down upon the Yi and vice versa. The reputation of the Yi is not good outside. There are many thieves and drug dealers. There is a high incidence of AIDS in Zhaojue County.

Xiao Fang explained her reaction to "the bad habits" of the Yi in terms of the broader perspective she brought, having lived outside the area. In her words, "比起纯彝族家庭 
出来的学生, 我会抽离一点来看这个问题[Compared with Yi students from a family where both parents are Yi, I can stand back and see the situation]".

Her attitudes towards the three languages of the programme, while to some extent predictable given her personal journey, are nonetheless interesting. Xiao Fang was clearly confident about her competence in Mandarin acquired during her formative years in Meishan. Participation in the YEC programme meant that she had greater contact with Yi and Yi-related culture both in and outside the classroom. Given her limited competence in the language, she inevitably found Yi study very challenging. At the end of the first year, progress had been very slow. Although Xiao Fang had acquired a basic understanding of the Yi script, her self-assessment of her overall competence was "basic". She was struggling. “明天马上要考彝文了, 我真的不知道怎么去参加 考试 [The Yi exam is due tomorrow. I really have no clue of how to manage it]".

Her attitude towards English, however, was very favourable. Xiao Fang was confident that she had made progress in both listening comprehension and speaking, and felt that the approach used in teaching was more effective than the examination driven curriculum she had experienced in middle school. She summed this experience up in the following way:

\section{读大学的价值也许在与开始明白, 学习应该是一个持续恒动的过程。不是为了 证书、文凭或者是发财。}

The value of studying in a university is probably that [we] gradually realize that learning is a continuous and dynamic process. It is not for the certificates, diplomas or making a fortune.

\section{Hei Ga}

Hei Ga, the son of a home maker and a lorry driver, is a Model I student whose contact with the Yi language started very early. His first three years of primary education were spent in a local village school where there were only three Yi teachers. Children were taught Chinese and maths mainly through the medium of Yi. At this point Hei Ga passed the entrance exam for another better-resourced school at county level, seventy kilometres away from his village where he became a boarder. Like many other Yi children, he went back home only during the winter and summer 
vacations. In this new primary school, Yi was taught as a subject for the first time, further strengthening his competence in the language.

After entering junior middle school in Zhaojue at the age of 13 or 14, the population was more mixed. For the first time, the majority of teachers were Han Chinese and the medium of instruction was Chinese. As a young boarder, he often stayed up late playing computer games with friends in the evenings at local internet cafés and, as a result, he would be unable to concentrate much of the next day. When his teacher informed his parents of what was happening, they transferred him to another middle school in Xichang, which was closer to home and where he retook the second year. And finally in the third year, the whole family - parents and two siblings - moved from their village to Xichang in order to monitor Hei Ga's study. At that point, he was a day student.

Although Chinese remained the medium of instruction, Hei Ga started studying Yi more systematically as a subject for a small number of sessions each week, something he very much enjoyed. This arrangement continued until he was accepted as a Model I student in the senior sector of the same school. He did not disappoint his family. In 2013, he came fifth out of all the students in the three Model I middle schools in the Liangshan area in the entrance exams for universities and colleges, with a very high language score (71 out of 75) in Yi. His original choice was a top national university. Unfortunately, because only three vacancies were allocated to Model I Yi students from Sichuan in this university that year, Hei Ga was not admitted and also missed the opportunity to apply for other more prestigious universities. As his fall back position, he was admitted to the case study university.

Although Hei Ga's self-assessment of his Chinese competence was 'fluent' (compared with Xiao Fang's self-assessment of 'excellent'), he scored higher than Xiao Fang in the university entrance exam for Chinese. Of the different pathways available, however, he was not interested in either the Yi-Chinese or the Yi-Japanese programme. His ultimate goal, on the advice of his former class teacher, was to take the entrance exams for graduate school where English proficiency was critical in gaining a place. Although he had a low score in the English exam, his only option was thus to enroll on the YEC programme. 
The simultaneous study of three languages in YEC was by no means smooth. $\mathrm{He}$ identified a number of contributory factors:

高中同学基础都差不多，老师遇到大家不懂地方还会用汉语解释一下。 到这边来，大部分二类同学考得都比我们好。老师讲的他们大部分都听 得懂，相对老师停下来再多解释一下的机率就少了。听着，听着，就不 懂了。

In high school, the [English] levels of all my peers were close. The teacher therefore would explain in Chinese the [English] points we found confusing when there was anything we didn't understand. But here, the majority of Model II students score better than us [i.e. Model I students] [in the English entrance exam] and they can understand most of what the teachers say. This means the teacher explains things even less. So, as time has gone by, I haven't been able to understand more and more.

This was clearly a dilemma for a Model I student like Hei Ga. As explained earlier, most Model I students admitted to the YEC programme had much higher overall scores than Model II students. Yet, there was a general feeling among Model I students that Model II students' English competence was stronger, enabling them to follow in English classes while Model I students struggled. When asked why they had not communicated this issue to the teacher, Hei Ga explained that they thought it was too embarrassing to ask them to slow down or explain things in greater detail when only a small number of students were affected.

These differences were the source of some discomfort for Hei Ga:

我原本想，我们一类模式的考到这来分数一定是最低的。结果来到这， 身边都是考 300 多的[黑呷考了 471]。在高中时特别是高三，差不多大 家都很努力。看到那种氛围, 自己都不好意思坐到教室不学习。而这里 的同学很多都考 300 多分，感觉他们高考时没怎么努力。来这里后，依 然都还是那种状态。几个人在一起, 潜移默化, 互相影响。 
Initially, I thought that we Model I students must have had the lowest marks on the programme. But it turned out to be that many of our classmates scored just above 300 [Hei Ga scored 471]. In high school, and especially in the third year, almost everybody worked hard. In that atmosphere, you would feel embarrassed if you didn't do much in class. But here [on the programme], there were so many people who scored 300 who it seemed hadn't worked hard in the past. So they carried on with that mindset on the [new programme]. As I started mixing with them, it bothered me more and more.

Hei Ga summarised his early days in the University in terms of: "上了一学期什么都 没学到[After one semester's study, I haven't learned a thing]". He recognised, however, that he needed to take responsibility for the situation and in the summer vacation following the interview, he decided to register for extra English courses in the hope that it would still be possible to go to graduate school.

When Hei Ga was asked whether he planned to go to other big cities for employment if he could not find a place in graduate school, he replied in the negative.

黑呷：就想找到工作后就回去。因为那边有亲戚, 对家乡有一种向往。 采访人：那你还是想回来？

黑呷：对。因为小时候在小学读书的时候哭了很多, 因为想家。。。

Hei Ga: I am thinking of going back to my [hometown] as long as I can pass the entry requirements for a job because I've got relatives there. I have a longing for home.

Interviewer: So, you still want to come back?

Hei Ga: Yes. This is because when I was young in primary school, I cried so much because I was homesick ...

The River of Life mapped out by Hei Ga twists and turns but in the end, it seems likely that it will return to its source. 


\section{Discussion}

The three case studies - A Hai, Xiao Fang and Hei Ga - illustrate the diversity of students in the YEC programme.

Various life events had steered them towards this programme. For A Hai, the discovery of the world of books in the wake of a series of unhappy school experiences was a pivotal event. In the case of Xiao Fang, the move to live with her parents following the death of her maternal grandparents allowed her to make more frequent visits to her paternal grandmother and was the trigger for her to reappraise Yi language and culture: up to this point, she appeared to have accepted uncritically Han prejudices and stereotypes. For Hei Ga, too, the move to a new school, together with the sacrifice of his whole family in moving with him, was important, allowing him the opportunity to excel as a Model I student.

We were also interested in how students positioned themselves in relation to the three languages of the programme. Two of the three (A Hai and Hei Ga) had been immersed in the language from birth while Xiao Fang had only been exposed to Yi on visits to her paternal grandparents. Their language histories at school were also variable. At primary school both A Hai and Hei Ga received a bilingual education, delivered by Yi and Han teachers and, in A Hai's case, it was not until Junior Middle School that the medium of instruction changed to Chinese only. In Hei Ga's case a move to another school offered greater opportunity for more formal study of Yi and ultimately admission to the YEC programme as a Model I student. In contrast, Xiao Fang's first experience of Yi in an educational context was at the age of 17 when she moved back to live near her paternal grandparents. These three cases illustrate the considerable variation in the levels of Yi proficiency of students on the programme.

YEC is, of course, a trilingual programme which aims to promote not only Yi but also Chinese and English. There was little variation in students' competence in Mandarin. Xiao Fang, for instance, having grown up in a Chinese speaking household and attended school in a Han-dominated area, felt completely at ease with the language. Chinese was also the dominant language of A Hai while Hei Ga, as a Model I student, appeared to have achieved a more balanced bilingualism. 
The situation was more polarised in the case of English. Hei Ga was clearly struggling in spite of his strong motivation to learn the language; he was also troubled by perceived differences in understanding and performance between Model I and Model II students and by the embarrassment which prevented him and his peers asking teachers to slow down. Xiao Fang's confidence in her progress in English and A Hai's lack of comment on this matter suggest a very different relationship with the language and offer support for Hei Ga's observation about the better understanding of Model II students.

The overall picture which emerges, however, would seem to support the conclusion of Hu's study (2007, p.281) of Dai and Hani ethnic minority school students in Yunnan, another Southwestern province:

The ethnic minority students' formal bilingual education has an insignificant impact on their L3 learning. The impact only affects the students' abstract or deep level [of] cognition. On the concrete or superficial level knowledge, such an impact has declined. It is noticeable that bilingual education is not the equivalent of Han Language proficiency even in Chinese [language] situations with the trends of assimilation by the Han.

It is important, however, to bear in mind the role of Chinese in the L3 learning of minority speakers. English classes are delivered through L2 Chinese rather than Yi. While YEC students' self assessment of their Chinese skills was relatively high, it is possible that some, including Hei Ga, had not yet reached the higher threshold of competence in Chinese required for skill transfer from bilingualism to trilingualism. (Cummins, 1979). Other factors in teaching and learning, of course, also come into play, such as attitudes, pedagogical issues, and curriculum design.

What, then, are the implications for the delivery of the programme and the learning outcomes of students? In short, provision for such a diverse group of students in a trilingual programme is extremely challenging. Initiatives such as the Great Western Development plan (Li, Zhang, \& Edwards, 2015) aim to raise educational standards and equalize opportunities for minority populations. While the awarding of additional points in university and college entrance examinations allows greater access to higher education for minority students, the poor educational achievements of the students on entry place heavy demands on those responsible for programme delivery; so, too, do their varying levels of competence in both Yi and English. 
While the case study students - and indeed all of their peers (Liu, forthcoming) were united in recognizing the pragmatic value of English as a language of wider communication and key to future employment prospects, their apparent differences in levels of understanding are a matter of concern. Even more challenging are both the low levels and the range of competencies in $\mathrm{Yi}$, which require thoughtful pedagogical responses. Mixed ability groups of this kind are extremely challenging for both teachers and the production of effective teaching materials. That said, the importance of the programme in enhancing the social status and academic potential of Yi students cannot be underestimated. Although issues remain about the learning outcomes achieved, the pragmatic gains associated with YEC are substantial in terms of access to future employment in their home region and opportunities for further study.

\section{Conclusion}

Discussion of trilingual education in the context of higher education in China has been conspicuous through its absence. In this article we have attempted, firstly, to throw light on a phase of education which, to date, has received little attention; and, secondly, to illustrate the extent of diversity in students enrolled upon a Yi-EnglishChinese trilingual programme and the challenges this poses for those involved in delivery. More specifically, we have drawn attention to the life events - including family relocation and a change of schools - which have steered students in the direction of the trilingual YEC programme. We have demonstrated the different ways in which students position themselves in relation to the three languages, highlighting, in particular, the varying levels of competence. Finally, we have considered the implications for the delivery of the programme and the learning outcomes for the students: the weak academic backgrounds of Yi students, together with limited teaching resources and the absence of appropriate pedagogies, create formidable challenges for teachers and sometimes disappointing outcomes for students. These weaknesses, are counterbalanced by the gains associated with the programme, such as a stronger sense of ethnic identity, greater access to employment in their home region and admission to postgraduate programmes.

It is hoped that the perspectives on trilingual education offered by this study, including the particular Chinese political and sociolinguistic dimensions, will 
contribute to a deeper understanding of adult multilingualism in many other contexts. In a similar vein, other researchers may find the little known River of Life technique a valuable tool for allowing adult multilinguals to explore their experiences, opinions and concerns.

\section{Appendix}

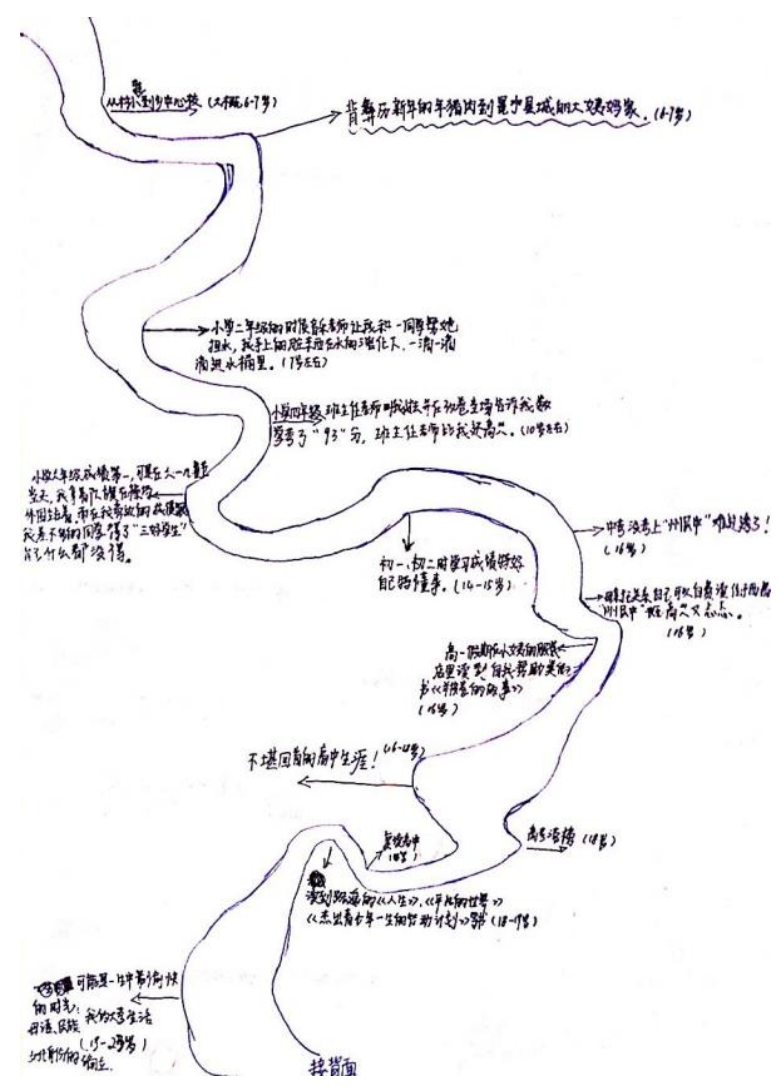

Section of a participant River of Life drawing

\section{References}

Adamson, B., \& Feng, A. (2009). A comparison of trilingual education policies for ethnic minorities in China. Compare: A Journal of Comparative and International Education, 39(3), 321-333. doi: 10.1080/03057920802436258 
Cabaroglu, N., \& Denicolo, P. (2008). Exploring student teacher belief development: An alternative constructivist technique, snake interviews, exemplified and evaluated. Personal Construct Theory \& Practice, 5, 28-40.

Cenoz, J. (2014). Preface. In A. Feng \& B. Adamson (Eds.), Trilingualism in Education in China: Models and Challenges. London: Springer.

Cummins, J. (1979). Linguistic interdependence and the educational development of bilingual children. In C. Baker \& N. H. Hornberger (Eds.), An introductory reader to the writings of Jim Cummins (pp. 63-95).

Dai, Quingxia et al (2000) Zhongguo shaoshuminzyu yuyan wenzi yanjiu \{Applied studies of Chinese minority nationality language and orthographics]. Kunming: Yunnan minzu chubanshe [Yunnan Nationalities Press \}.

Denicolo, P., \& Pope, M. (1990). Adults learning - Teachers thinking. In C. Day, M. L. Pope \& P. Denicolo (Eds.), Insights into teachers' thinking and practice (pp. 155-169). London: Falmer.

Feng, A. (2005). Bilingualism for the minor or the major? An evaluative analysis of parallel conceptions in China. International Journal of Bilingual Education and Bilingualism, 8(6), 529-551. doi: 10.1080/13670050508669067

Feng, A. (2007). Introduction. In A. Feng (Ed.), Bilingual education in China: Practices, policies and concepts. Clevedon: Multilingual Matters.

Feng, A. (2012). Multilingual education in China. In C. A. Chapelle (Ed.), The Encyclopedia of Applied Linguistics. West Sussex: Wiley-Blackwell.

$\mathrm{Hu}$, D. (2007). 云南少数民族三语教育 [Trilingual education of members from ethinc minority nationalties in Yunnan]. Kunming: Yunnan University Press.

Hu, R., Fu, L., \& Zhang, Y. (2003). Four challenges in the development of education and human resources in China [教育与人力资源开发面临的四大挑战]. http://www.lianghui.org.cn/chinese/zhuanti/281525.htm

Li, D., Zhang, X., \& Edwards, V. (2015). Innovation and change in English teaching in the western provinces of China: The impact of overseas training. In J. C.-K. L. Lee, Z. Y. Yu, X. H. Huang \& E. H.-F. L. Law (Eds.), Educational development in Western China: Towards quality and equity. Hong Kong: Sense Publishers

Li, X., Hai-Lai, W., Liao, H., \& Luo-Hong, C. (2015). Study of the psychological quality of "A Pattern" college students of Yi nationality: Taking Xichang College as an example [“一类模式” 宷族大学生心理素质现状研究: 以西昌 学院一类模式彝族大学生为例]. Journal of Xichang College, 29(4), 148-150.

Liu, J. (forthcoming). Trilingual education model of Chinese university minority students: A case study (Unpublished doctoral thesis). the University of Reading, Reading, UK.

Liu, Y. (1998). Educational utilitarianism: Where goes higher education? Higher education in post-Mao China, 121-140.

Mair, V. H. (1991). What is a Chinese "dialect/topolect"?: Reflections on some key Sino-English Linguistic Terms. Sino-Platonic Papers(29).

Pope, M. L., \& Denicolo, P. (1986). Intuitive Theories: A Researcher's Dilemma: Some Practical Methodological Implications. British Educational Research Journal, 12(2), 153-166. doi: 10.2307/1500708

Pope, M. L., \& Denicolo, P. (2001). Transformative education: Personal construct approaches to practice and research. London: Whurr Publisher.

Teng, X., Yang, H., \& Yang, Q. (2014). Multicultural education and ethnic integration: A case study of girls' education in the Lahu area. In J. Leibold \& 
Y. Chen (Eds.), Minority education in China: Balancing unity and diversity in an era of critical pluralism. Hong Kong: Hong Kong University Press.

Tsung, L. (2012). Language and power: Tuanjie hua, an Yi-Han mixed language. International Journal of the Sociology of Language, 215, 63-77.

Wang, T. (2015). 少数民族高考加分不再 “阳光普照” [Additional scores is no longer "generic" for ethnic minority students in college and university exams]. http://www.mzb.com.cn/html/report/150430901-1.htm

Yu, k., Stith, A. L., Liu, L., \& Chen, H. (2012). Tertiary education at a glance China Vol. 24. Global perspectives on higher education (pp. 1 online resource (xiv, 287 p.)). Retrieved from http://site.ebrary.com/lib/reading/Doc?id=10546374

Zhao, H. (2015). Yi middle school students' motivations for Chinese learning: A case study of Xichang Minzu Middle School in Liangshan Prefecture 彝 族中学生汉语文学习动机的研究——以凉山州西昌市民族中学为个案.

(Ph.D), Minzu University of China, Beijing. 